Психология. Журнал Высшей школы экономики.

2017. T. 14. № 4. C. 698-716. DOI: 10.17323/1813-8918-2017-4-698-716

\title{
КТО ПРОДОЛЖАЕТ УЧАСТВОВАТЬ ВО ВТОРОМ ЭТАПЕ ИССЛЕДОВАНИЯ? РОЛЬ ЛИЧНОСТНЫХ ХАРАКТЕРИСТИК
}

\section{C.А. ЩЕБЕТЕНКО}

${ }^{a}$ Пермский государствениьй национальньй исследовательский университет, 614990, Россия, Пермь, ул. Букирева, д. 15

\section{Резюме}

Целью исследования было изучение того, являются ли черты личности предиктором истощения выборки, происходящего в исследовании с двумя волнами сбора данных как частном случае лонгитюда. Методологически проблема решалась в терминах пятифакторной теории личности (McCrae, Costa, 2013). Исследование проводилось в два этапа. На этапе 1 студентов приглашали принять участие в психологическом исследовании, проводившемся в учебной аудитории, где они выполняли основной набор тестов. На этапе 2 участники дистанщионно заполняли вопросник и 277 из 1030 участников выслали файл с выполненным тестом исследователю по электронной почте. Доброжелательность, добросовестность и интроверсия предсказывали, что участник продолжит исследование на втором этапе. Посредством логистического регрессионного анализа оценивался вклад в эти эффекты рефлексивных характерных адаптаций - метачерт и установок на черты. Метачерты представляют собой суждения индивида о том, как его черты личности воспринимаются значимыми другими, в данном случае - родителями. Установки на черты представляют собой валентные (положительные/отрицательные) оценки данной черты индивидом без прямого отнесения к своей личности. Рефлексивные характерные адаптации вносили инкрементный вклад в вероятность участия в этапе 2, в то время как вклад собственно черт личности был элиминирован. Истощение выборки предсказывалось несколькими метачертами, а также установками на несколько черт личности. Амбивалентная роль метачерт и установок на черты обсуждается в терминах рефлексивно-импульсивной модели Ф. Штрака и Р. Дойча. Была эмпирически поддержана модель, при которой черты личности (экстраверсия, доброжелательность, добросовестность) производят непрямые эффекты на истощение выборки, опосредованные рефлексивными характерными адаптациями. В целом небольшие размеры коэффициентов детерминации означают, что вклад личностных характеристик в истощение выборки следует отнести к разряду малых, но существенных.

Ключевые слова: истощение выборки, черты личности, Большая Пятерка, характерные адаптации.

Искажения выборок, связанные с добровольным участием в исследовании, являются одной из ключевых проблем получения эмпирических данных в психологии и прочих науках и практиках, имеющих дело с человеком как объектом изучения (Давыдов, 1990; Дружинин, 2000 ). 
Общепсихологические исследования формируют свою эмпирическую базу преимущественно на данных людей, добровольно согласившихся на участие. Согласие на участие имеет, естественно, и обратную сторону несогласие на участие, которое может стать проблемой как в контексте кросс-секционных (неслучайные отсутствующие данные), так и лонгитюдных исследований (истощение выборки - Корнилов, 2011). Такие ситуации создают почву для возникновения систематических ошибок отбора данных (Власов, 2007), приводящих, в частности, к ошибкам I и II родов при тестировании гипотез. Истощение выборки может происходить под действием различных факторов, ряд из которых обсуждается ниже. Среди них, по всей видимости, определенное место занимают личностные характеристики. В данной статье представлены результаты эмпирического исследования вклада личности в истощение выборки, возникающее в исследованиях с двумя волнами сбора данных (И2ВД).

\section{Лонгитюд, волны сбора данных и истощаемость выборки}

И2ВД широко используется при осуществлении экспериментальных и квазиэкспериментальных схем для увеличения точности измерения эффекта путем контроля интраиндивидуальной изменчивости (Корнилов, 2011). Такое исследование можно считать простейшей формой лонгитюда, учитывая сохраняющийся плюрализм в трактовке последнего (Корнилов, 2011; Menard, 2002). И2ВД, однако, обладает рядом специфических ограничений в плане получаемых выводов (Ployhart, Vandenberg, 2010). В частности, истощение выборки (или выпадение испытуемых) является одним из основных источников угроз валидности как для И2ВД, так и для лонгитюда (Menard, 2002). Эффект истощения, очевидно, имеет место и в кросс-секционных исследованиях, так как при такой схеме изначально «выпадают» те потенциальные участники, которые не хотят или не могут участвовать в исследовании добровольно.

\section{Добровольное согласие на участие в исследовании}

Проблема добровольного информированного согласия участников достаточно хорошо разработана в современных науках о человеке (Rosenthal, Rosnow, 1975). Рассматриваются правовые и этические аспекты добровольного участия в биомедицинском исследовании (Косарев, Бабанов, 2009), регулируемые деятельностью этических комитетов (Чепракова и др., 2011); определяют ся права участников психологического исследования (American Psychological Association, 2010). Потенциальный участник может быть привлечен к исследованию разными способами (Saliba, Ostojic, 2014): обращением к возможным респондентам через рекламные сообщения, перехватом (interception) на улице, телефонным обращением, интернетрекрутментом, включая специализированные ресурсы типа Survey Monkey и т.п.

Что может повлиять на решение индивида об участии в исследовании? Перечень возможных причин 
достаточно широк: от социальноэкономических факторов (Тренева и др., 2014; Satherley et al., 2015; Singer, Bossarte, 2006) до гендерных особенностей. Женщины с большей готовностью принимают участие в биомедицинских и психологических исследованиях, чем мужчины (например: Адмиральская, 2009; Тренева и др., 2014). Большему отсеву подвержены одинокие, менее образованные, а также живущие в городах в сравнении с имеющими постоянного партнера, более образованными и живущими в сельской местности (Richter et al., 2014; Satherley et al., 2015). Склонность не отвечать (non-response bias) может быть обусловлена тревогами приватности и конфиденциальности, боязнью насилия (например, впустить в дом незнакомцаинтервьюера) или индивидуальными чертами интервьюера (например, внешность и пол - Schräpler et al., 2010). Степень согласия на участие может варьироваться. Различают (Rogelberg et al., 2003) ответ (respondence), активный отказ (active nonrespondence; внятное однозначное заявление о нежелании участвовать) и пассивный отказ (согласие при последующем неучастии по разным причинам). Согласие на участие может быть связано со статусом изучаемых показателей, их «историей» в жизни потенциальных респондентов. Так, согласие матерей новорожденных на участие в аллергологическом исследовании находилось в зависимости от более частого проявления соматических заболеваний среди родственников ребенка, включая аллергические проявления (Тренева и др., 2014).

Психологические факторы составляют отдельный пласт обсуж- даемой проблемы. Так, например, люди могут руководствоваться разными мотивами, когда они соглашаются на участие в исследовании (Groves et al., 2000). Утверждается, что существует три основных причины добровольного согласия (Singer, Bossarte, 2006): (1) альтруизм (pecпондент тем самым выполняет некое социальное обязательство), (2) причины, связанные с опросом (респонденты заинтересованы темой или испытывают симпатию к интервьюеpy), и (3) эгоистические причины (респондентам «просто нравится» выполнять тесты и анкеты, они получают за это денежную или иную компенсацию).

Варьирование мотивации участия в исследовании может приводить как к положительным, так и к отрицательным с точки зрения сбора информации эффектам от диспропорционально высокой вовлеченности до вероятной принадлежности получаемой выборки к группе, в которую входит сам исследователь (Адмиральская, 2009). Возникает проблема того, как мотивация влияет на поведение респондентов включая их реакции и ответы в ходе диагностики (Church, 1993; Singer, Bossarte, 2006).

\section{Добровольное участие, истощение выборки и черты личности}

Черты личности выражают собой индивидуальные различия в поведении и мотивации человека (John et al., 2008). Можно предположить, что они вносят вклад и в истощение выборки. Эта проблема изучается, по крайней мере, в течение последнего полувека (например: Lubin et al., 
1962; Rosenthal, Rosnow, 1975; Saliba, Ostojic, 2014). За это время накоплен существенный эмпирический материал и предложены его разнообразные интерпретации.

P. Розенталь и Р. Росноу (Rosenthal, Rosnow, 1975) утверждали, что волонтеры исследований отличаются рядом личностных характеристик, среди которых поиск возбуждения, необычность (unconventionality), общительность (необязательно экстраверсия), альтруизм и самораскрытие. Анализируя исследования, выполненные в рамках пятифакторной модели (Goldberg, 1993; McCrae, Costa, 2013), Н. Сазерлей с соавт. приходят к заключению об «отсутствии консенсуса между редкими исследованиями связи личности и истощения выборок» (Satherley et al., 2015 , р. 6), а Д. Рихтер с соавт. (Richter et al., 2014) добавляют к этому замечание о небольших размерах получаемых эффектов. В частности, Б. Робертс с соавт. (Roberts et al., 2006) в метаанализе 92 лонгитюдов не обнаружили систематической связи между истощением выборок и средним уровнем онтогенетической изменчивости черт личности.

Доброжелательность и открытость опыту предсказывали готовность участников в дополнение к основному исследованию предоставить информацию о прошлых результатах выполнения теста АСТ, которые учитываются при поступлении в колледж, а также принять участие в другом, лонгитюдном, исследовании (Dollinger, Leong, 1993). Позднее было показано, что эти черты предсказывают и реальное участие во втором раунде панельного опроса (Salthouse, 2014). Пассивный и активный отказы от участия были отрицательно связаны с добросовестностью (Rogelberg et al., 2003). Готовность участия в лонгитюде коррелировала с экстраверсией (Dollinger, Leong, 1993), которая, по мнению авторов, способствует добровольному участию в исследованиях, требующих межличностных взаимодействий. Однако был получен и обратный эффект: число экстравертов среди «бесследно пропавших» участников лонгитюда - равно как и число эмоционально нестабильных и недобросовестных индивидов было выше, чем число интровертов, эмоционально стабильных и добросовестных индивидов. Позднее эти результаты получили подтверждение при использовании данных голландского панельного лонгитюда в части добросовестности, экстраверсии (Lugtig, 2014) и эмоциональной стабильности (Saßenroth, 2013). Открытость была связана с длительностью участия в голландских, немецких и новозеландских лонгитюдах (Richter et al., 2014; Saßenroth, 2013; Satherley et al., 2015). В одном из исследований (Satherley et al., 2015) было показано положительное влияние на длительность участия искренности (humility) - черты, входящей в модель HEXACO (Ashton, Lee, 2007). На основании обзора опубликованных данных была сформулирована следующая гипотеза.

Н1: Участие респондента во второй волне исследования с двумя волнами сбора данных будет более вероятно при высоких значениях доброжелательности, добросовестности и открытости опыту, а также при низких значениях экстраверсии и нейротизма. 


\section{Добровольное участие и черты личности: опосредованная взаимосвязь}

Эффекты черт личности на социально значимое поведение часто опосредованы установками в отношении данного объекта (Gallego, Oberski, 2012). Например, связь между искренностью-сдержанностью (honesty/humility) и кооперацией была обусловлена ориентацией индивида на социальные ценности (Hilbig et al., 2013). Непрямая связь черт личности с поведенческими последствиями постулируется в пятифакторной теории (FFT; McCrae, Costa, 2013). Согласно FFT, черты личности как «базовые тенденции» (basic tendencies) производят на поведение индивида и факты его биографии (objective biography) непрямые воздействия, опосредованные факторами, именуемыми «характерными адаптациями» (characteristic adaptations). Ранее в этой связи мы выделили их рефлексивную разновидность (Шебетенко, 2015б), представляющую собой рефлексию и мониторинг индивидом своих индивидуальных личностных характеристик. Различаются четыре рефлексивные характерные адаптации (РХА; подробнее см.: Там же): диспозициональная эффективность, установки на черты, метачерты и метаустановки на черты. Ранее было обнаружено несколько примеров опосредующей роли PXA. В частности, положительная установка на открытость опыту опосредовала связь открытости опыту с положительным отношением к произведениям живописи (Щебетенко, Тютикова, 2015). Установка на экс- траверсию опосредовала связь экстраверсии с социометрическим статусом (Балабина, 2015). PXА в сравнении с собственно чертами личности вносили инкрементный вклад в предсказание академической успеваемости в университете и поведение студентов в социальных сетях (Шебетенко, 2015a; Shchebetenko, 2016). Таким образом, РХА могут обладать инкрементным потенциалом предсказания критериальных показателей в сравнении с чертами личности.

В данной работе изучались две PXA - метачерты и установки на черты. Метачерты представляют собой суждения индивида о том, как его черты личности воспринимаются значимыми другими (Шебетенко, 2015б). Установка на черту представляет собой валентную (положительную/отрицательную) оценку данной черты индивидом без прямого отнесения к собственной личности (Shchebetenko, 2014). Предполагалось, что эти РХА могут осуществлять инкрементные вклады в вероятность участия респондентов во втором этапе И2ВД. Более того, предположительно черты личности оказывают на вероятность участия респондентов непрямые эффекты, опосредованные PXА.

H2.1: Установки на черты и метачерты производят инкрементные вклады в предсказание участия во второй волне исследования в сравнении с чертами личности.

H2.2: Черты личности вызывают непрямые эффекты, опосредованные установками на черты и метачертами, на участие во второй волне исследования. 


\section{Метод}

\section{Участники}

В исследовании приняли участие 1030 студентов Пермского госуниверситета, в возрасте от 17 до 38 лет $(\mathrm{M}=19.65, \mathrm{SD}=1.72)$. Одна участница не сообщила своего возраста. Среди участников была 691 женщина $(67.1 \%)$.

\section{Прочедура и вопросники}

Исследование проводилось в два этапа.

\section{Этап 1: первичная выборка}

На этапе 1 студентов приглашали принять участие в психологическом исследовании, проводившемся в учебной аудитории. Потенциальным участникам вкратце излагалась процедура и общая легенда цели исследования, представлявшаяся как «изучение характера человека». Хотя перед началом основных процедур студентам сообщалось, что они могут отказаться от дальнейшего участия, в действительности подавляющее большинство согласились, за исключением 11 человек (1.06\% от общей выборки).

Участникам сообщалось о втором, заочном, этапе исследования (детали см. ниже). Единственным стимулом к участию на этапе 2 было обещание предоставить «более детальный отчет об исследовании, включая личный профиль результатов». Студентам не предлагались учебные баллы (кредиты) за участие. Исследователь не был преподавателем тестируемых студенческих групп.
На этапе 1 диагностировались характеристики личности. Участники заполняли русскую версию (Shchebetenko, 2014) 44-пунктного теста Big Five Inventory (BFI; John et al., 1991; John et al., 2008), а также его модификации, созданные для измерения метачерт и установок на черты (Шебетенко, 2015б). Подшкалы стандартной версии BFI показали хорошую и приемлемую внутреннюю согласованность $(\alpha=0.78,0.68,0.80$, $0.79,0.81)$ для экстраверсии, доброжелательности, добросовестности, нейротизма и открытости опыту соответственно.

Для измерения метачерт BFI был несколько изменен. С учетом того, что участники в основном находились в возрасте юности и ранней взрослости, мы предположили, что их родители могут считаться значимыми другими (Malloy et al., 1997). Общая инструкция была следующей:

«В этом блоке вы должны определить то, как, по вашему мнению, вас оценивают (или оценивали) ваши родители. Считают (или считали) ли они вас человеком, обладающим данными качествами или, напротив, их не имеющим? В том случае, если вы считаете, что они расходятся (или расходились) во мнении по поводу данного качества, используйте "метод средней оценки"».

Далее участникам предлагался стандартный список пунктов BFI c вводным предложением: «Мои родители считают (считали) меня тем, кто...» Каждый пункт оценивался по традиционной для BFI 5-балльной шкале. Подшкалы метачерт показали хорошую внутреннюю согласованность $(\alpha=0.81,0.75,0.86,0.81,0.83)$ для экстраверсии, доброжелательности, 
добросовестности, нейротизма и открытости соответственно.

Для измерения установок на черты общая инструкция BFI выглядела следующим образом: «Теперь вам предстоит оценить ряд личностных качеств с точки зрения их привлекательности для вас. Считаете ли вы то или иное свойство хорошим или плохим личностным качеством? Не имеет значения, есть ли у вас это свойство или нет: важно, нравится ли оно вам». Общее вводное предложение было следующим: «Я считаю это качество для человека..» Ответы варьировались от 1 («очень плохим») до 5 («очень хорошим»). Установка на экстраверсию показала слабую внутреннюю согласованность $(\alpha=0.57)$. Для увеличения надежности этой шкалы из нее были исключены три пункта: «сдержанность», «порождение энтузиазма» и «застенчивость». После этого шкала показала приемлемую внутреннюю согласованность $(\alpha=0.69)$. Остальные четыре подшкалы показали приемлемую и хорошую внутреннюю согласованность ( $\alpha=0.69,0.72,0.71,0.77)$ для доброжелательности, добросовестности, нейротизма и открытости.

\section{Этап 2: истощение выборки}

По окончании этапа 1 участников просили сообщить адреса их электронной почты ${ }^{1}$. Посредством этих адресов был осуществлен дебрифинг. Как отмечалось выше, студентам предлагали принять участие во второй, дистанционной, части исследования. Она представляла собой разновидность Теста реконструкции дня (Day Reconstruction Method - Kahneman et al., 2004). Те испытуемые, которые согласны были участвовать в дистанционном тесте, получали «более детализированный отчет об их личной диагностике». В соответствии с инструкцией участники должны были заполнять тест в электронном файле Word три раза в течение недели, а затем отправить файл на электронный почтовый адрес исследователя. Спустя месяц после этапа 1 была осуществлена рассылка бланков респондентам с напоминанием о возможности участия в этапе 2. В течение нескольких недель они высылали заполненные вопросники. Один участник выслал пустой бланк и был включен в категорию неучаствовавших. Файлы со всеми заполненными тестами прислали 277 человек (26.9\% от выборки на этапе 1) в возрасте от 17 до 29 лет ( $\mathrm{M}=19.70$, $\mathrm{SD}=1.51)$, среди них - 75 мужчин (27.1\%). Пол слабо положительно коррелировал с участием в этапе 2, тетрахорическая корреляция ${ }^{2} \boldsymbol{\rho}=0.13$, $p<0.001$. При этом женщины несколько более активно продолжали участие в исследовании, чем мужчины.

Конфиденциальность данных применительно к каждому участнику была сохранена. Администрация университета получила аналитический отчет о результатах исследования без предоставления каких-либо персональных данных студентов.

${ }^{2}$ Тетрахорическая и бисериальная корреляции рассчитывались посредством функций tetrachoric и biserial пакета psych в R. 


\section{Результаты}

\section{Черты личности и истощение вььборки}

Экстраверсия была связана слабо отрицательно с участием в этапе 2 , бисериальная корреляция $\rho=-0.11$, $p<0.001$, так что с ростом интроверсии увеличивалась вероятность продолжения участия. Доброжелательность и добросовестность были связаны слабо положительно с участием в этапе 2 ( $\rho=0.08, p=.007$, и $\rho=0.14$, $p<0.001$, соответственно).

\section{Рефлексивнье характернье} адаптации и истощение выборки

Установка на доброжелательность была связана с участием в этапе 2 положительно, а установка на нейротизм отрицательно, $\rho=0.16, p<0.001$, и $\rho=-0.10, p=0.002$. Метаэкстраверсия была связана с участием в этапе 2 отрицательно, а метадобросовестность - положительно, $\rho=-0.16$, $p<0.001$, и $\rho=0.17, p<0.001$.

\section{Инкрементньй вклад рефлексивных характерных адаптаций е истощение вьборки}

Для оценки инкрементного вклада РХА применялась иерархическая логистическая регрессия ${ }^{3}$. На шаге 1 в уравнение включался пол участника, на шаге 2 - показатели пяти черт личности, на шаге 3 - показатели пяти метачерт, на шаге 4 - показатели установок на пять черт личности.
Зависимой дихотомической переменной выступало участие в этапе 2 .

Из таблицы 1 следует, что РХА вносили инкрементный вклад в вероятность участия в этапе 2 , в то время как вклад собственно черт личности (экстраверсии, доброжелательности и добросовестности) был элиминирован. В частности, результаты шага 4 показывают, что участие в этапе 2 предсказывалось при метадобросовестности, метаоткрытости, метаинтроверсии и метавраждебности, а также при положительной установке на доброжелательность и отрицательных установках на добросовестность и нейротизм. При этом вклад пола в участие в этапе 2 оставался статистически значимым.

\section{Пятифакторная модель личности и истощение выборки}

Для оценки того, производят ли черты личности непрямые эффекты на истощение выборки, опосредованные РХА, использовались структурные уравнения ${ }^{4}$. Черты личности экстраверсия, доброжелательность и добросовестность трактовались как коррелирующие экзогенные переменные. Они были включены в модель, поскольку попарно коррелировали с участием в этапе 2. Метаэкстраверсия, метадоброжелательность и метадобросовестность, а также установки на доброжелательность и добросовестность трактовались как эндогенные медиаторы. Они были включены в модель, поскольку были производными

\footnotetext{
${ }^{3}$ Рассчитывалась посредством SPSS 23.

${ }^{4}$ Рассчитывались посредством AMOS 22.
} 
Таблица 1

Пол, черты личности, метачерты и установки на черты как предикторы участия в этапе 2 (иерархический логистический регрессионный анализ)

\begin{tabular}{|c|c|c|c|c|}
\hline \multirow[b]{2}{*}{ Предикторы } & \multicolumn{4}{|c|}{ Участие в этапе 2} \\
\hline & $B(S E)$ & $\chi^{2}$ Вальда, $p$ & $\begin{array}{c}\text { Отношение } \\
\text { шансов }[95 \% \mathrm{CI}]\end{array}$ & $\begin{array}{l}R^{2} \text { Кокса- } \\
\text { Снелла }\end{array}$ \\
\hline \multicolumn{4}{|l|}{ Шаг $1, \chi^{2}(1)=5.98, p<0.001$} & 0.006 \\
\hline Пол & $0.37(0.16)$ & $5.81,0.016$ & $1.45[1.07 ; 1.97]$ & \\
\hline \multicolumn{4}{|c|}{ Шаг $2 \Delta \chi^{2}(5)=25.12, p<0.001 ;$ Модель $\chi^{2}(6)=31.09, p<0.001$} & 0.030 \\
\hline Пол & $0.40(0.17)$ & $5.54,0.019$ & $1.48[1.07 ; 2.06]$ & \\
\hline Экстраверсия & $-0.38(0.11)$ & $11.59,0.001$ & $0.68[0.55 ; 0.85]$ & \\
\hline Доброжелательность & $0.12(0.14)$ & $0.69,0.406$ & $1.12[0.86 ; 1.47]$ & \\
\hline Добросовестность & $0.38(0.12)$ & $10.93,0.001$ & $1.47[1.17 ; 1.84]$ & \\
\hline Нейротизм & $0.02(0.11)$ & $0.02,0.893$ & $1.02[0.82 ; 1.27]$ & \\
\hline Открытость & $0.14(0.12)$ & $1.39,0.238$ & $1.15[0.91 ; 1.46]$ & \\
\hline \multicolumn{4}{|c|}{ Шаг $3 \Delta \chi^{2}(5)=17.06, \mathrm{p}=0.004 ;$ Модель $\chi^{2}(11)=48.15, p<0.001$} & 0.046 \\
\hline Пол & $0.33(0.17)$ & $3.65,0.056$ & $1.39[0.99 ; 1.94]$ & \\
\hline Экстраверсия & $-0.40(0.13)$ & $10.27,0.001$ & $0.67[0.52 ; 0.86]$ & \\
\hline Доброжелательность & $-0.12(0.17)$ & $0.50,0.478$ & $0.89[0.64 ; 1.23]$ & \\
\hline Добросовестность & $0.46(0.13)$ & $13.27,<0.001$ & $1.59[1.24 ; 2.03]$ & \\
\hline Нейротизм & $0.00(0.12)$ & $0.00,0.973$ & $1.00[0.80 ; 1.26]$ & \\
\hline Открытость & $0.20(0.15)$ & $1.61,0.204$ & $1.22[0.90 ; 1.64]$ & \\
\hline Установка на экстраверсию & $0.05(0.18)$ & $0.08,0.774$ & $1.05[0.74 ; 1.51]$ & \\
\hline $\begin{array}{l}\text { Установка } \\
\text { на доброжелательность }\end{array}$ & $0.60(0.22)$ & $7.55,0.006$ & $1.83[1.19 ; 2.81]$ & \\
\hline $\begin{array}{l}\text { Установка } \\
\text { на добросовестность }\end{array}$ & $-0.47(0.24)$ & $3.82,0.051$ & $0.63[0.39 ; 1.00]$ & \\
\hline Установка на нейротизм & $-0.45(0.21)$ & $4.55,0.033$ & $0.64[0.42 ; 0.96]$ & \\
\hline Установка на открытость & $-0.31(0.23)$ & $1.85,0.173$ & $0.74[0.47 ; 1.14]$ & \\
\hline \multicolumn{4}{|c|}{ Шаг $4 \Delta \chi^{2}(5)=22.05, p=0.001 ;$ Модель $\chi^{2}(16)=70.19, p<0.001$} & 0.066 \\
\hline Пол & $0.35(0.18)$ & $3.95,0.047$ & $1.42[1.01 ; 2.00]$ & \\
\hline Экстраверсия & $0.06(0.18)$ & $0.09,0.761$ & $1.06[0.74 ; 1.51]$ & \\
\hline Доброжелательность & $0.06(0.20)$ & $0.07,0.788$ & $1.06[0.71 ; 1.57]$ & \\
\hline Добросовестность & $0.14(0.19)$ & $0.58,0.445$ & $1.15[0.80 ; 1.66]$ & \\
\hline Нейротизм & $0.08(0.16)$ & $0.25,0.615$ & $1.09[0.79 ; 1.49]$ & \\
\hline Открытость & $-0.04(0.20)$ & $0.05,0.827$ & $0.96[0.65 ; 1.41]$ & \\
\hline
\end{tabular}


Таблица 1 (окониание)

\begin{tabular}{|l|c|c|c|c|}
\hline \multirow{2}{*}{\multicolumn{1}{|c|}{ Предикторы }} & \multicolumn{3}{|c|}{ Участие в этапе 2} \\
\cline { 1 - 4 } & $B(S E)$ & $\chi^{2}$ Вальда, $p$ & $\begin{array}{c}\text { Отношение } \\
\text { шансов [95\% СI] }\end{array}$ & $\begin{array}{c}R^{2} \text { Кокса- } \\
\text { Снелла }\end{array}$ \\
\hline Установка на экстраверсию & $0.13(0.19)$ & $0.46,0.497$ & $1.14[0.79 ; 1.65]$ & \\
\hline $\begin{array}{l}\text { Установка на } \\
\text { доброжелательность }\end{array}$ & $0.76(0.23)$ & $11.03,0.001$ & $2.13[1.36 ; 3.33]$ \\
\hline $\begin{array}{l}\text { Установка на } \\
\text { добросовестность }\end{array}$ & $-0.53(0.24)$ & $4.77,0.029$ & $0.59[0.37 ; 0.95]$ \\
\hline Установка на нейротизм & $-0.43(0.21)$ & $3.97,0.046$ & $0.65[0.43 ; 0.99]$ \\
\hline Установка на открытость & $-0.39(0.24)$ & $2.69,0.101$ & $0.68[0.43 ; 1.08]$ \\
\hline Метаэкстраверсия & $-0.58(0.16)$ & $12.93,<0.001$ & $0.56[0.41 ; 0.77]$ \\
\hline Метадоброжелательность & $-0.39(0.18)$ & $4.88,0.027$ & $0.68[0.48 ; 0.96]$ \\
\hline Метадобросовестность & $0.42(0.16)$ & $6.92,0.009$ & $1.52[1.11 ; 2.08]$ \\
\hline Метанейротизм & $-0.13(0.16)$ & $0.64,0.425$ & $0.88[0.65 ; 1.20]$ \\
\hline Метаоткрытость & $0.36(0.18)$ & $3.91,0.048$ & $1.44[1.00 ; 2.05]$ & \\
\hline
\end{tabular}

Примечание. Полужирным шрифтом выделены переменные, вносящие статистически значимый вклад.

включенных в модель черт, а также, судя по результатам регрессионного анализа, вносили инкрементный вклад в участие в этапе 2. Ошибки установок на доброжелательность и добросовестность свободно коррелировали между собой. Ошибки метадоброжелательности и метадобросовестности также свободно коррелировали. Метадоброжелательность производила эффект на установку на доброжелатель- ность. Участие в этапе 2 трактовалось как эндогенная зависимая переменная. Матрица ковариаций анализировалась посредством асимптотически непараметрического (asymptotically distribution-free) взвешенного метода наименьших квадратов (weighted least squares, WLS; Browne, 1984) . $^{5}$

Эта модель хорошо объясняла полученные данные, $\chi^{2}(20)=55.65$, $p<0.001^{6}, \mathrm{RMR}=0.014, \mathrm{GFI}=0.986$,

${ }^{5}$ Поскольку в качестве зависимой переменной использовалась порядковая переменная, выраженная в дихотомической шкале, применение традиционного метода максимального правдоподобия (maximum likelihood, ML) неадекватно. Напротив, WLS показал высокую адекватность в оценках моделей с дихотомическими порядковыми переменными при условиях небольшого числа оцениваемых параметров и достаточно большой выборки (Flora, Curran, 2004).

${ }^{6}$ Инфляция $\chi^{2}$ была продемонстрирована в исследовании WLS для порядковых переменных средствами Монте-Карло (Flora, Curran, 2004). 
$\mathrm{CFI}=0.975$, RMSEA $[90 \% \mathrm{CI}]=0.042$ $[0.029 ; 0.055], p($ RMSEA $<0.05)=0.845^{7}$. Коэффициенты регрессии (см. рисунок 1) свидетельствовали о следующем. Метаэкстраверсия опосредовала отрицательный эффект экстраверсии на участие в этапе 2. Доброжелательность производила амбивалентный эффект на участие в этапе 2. С одной стороны, она предсказывала положительную установку на эту черту, которая, в свою очередь, способствовала участию в этапе 2. С другой стороны, доброжелательность предсказывала повышенную метадоброжелательность, которая, однако, способствовала неучастию в этапе 2. Добросовестность также производила амбивалентный эффект. С одной стороны, она предсказывала положительную установку на эту черту, которая, в свою очередь, препятствовала участию в этапе 2. Однако в то же время добросовестность предсказывала повышенную метадобросовестность, которая способствовала участию в этапе 2.

\section{Модель предикторов истощения выборки}

Рисунок 1

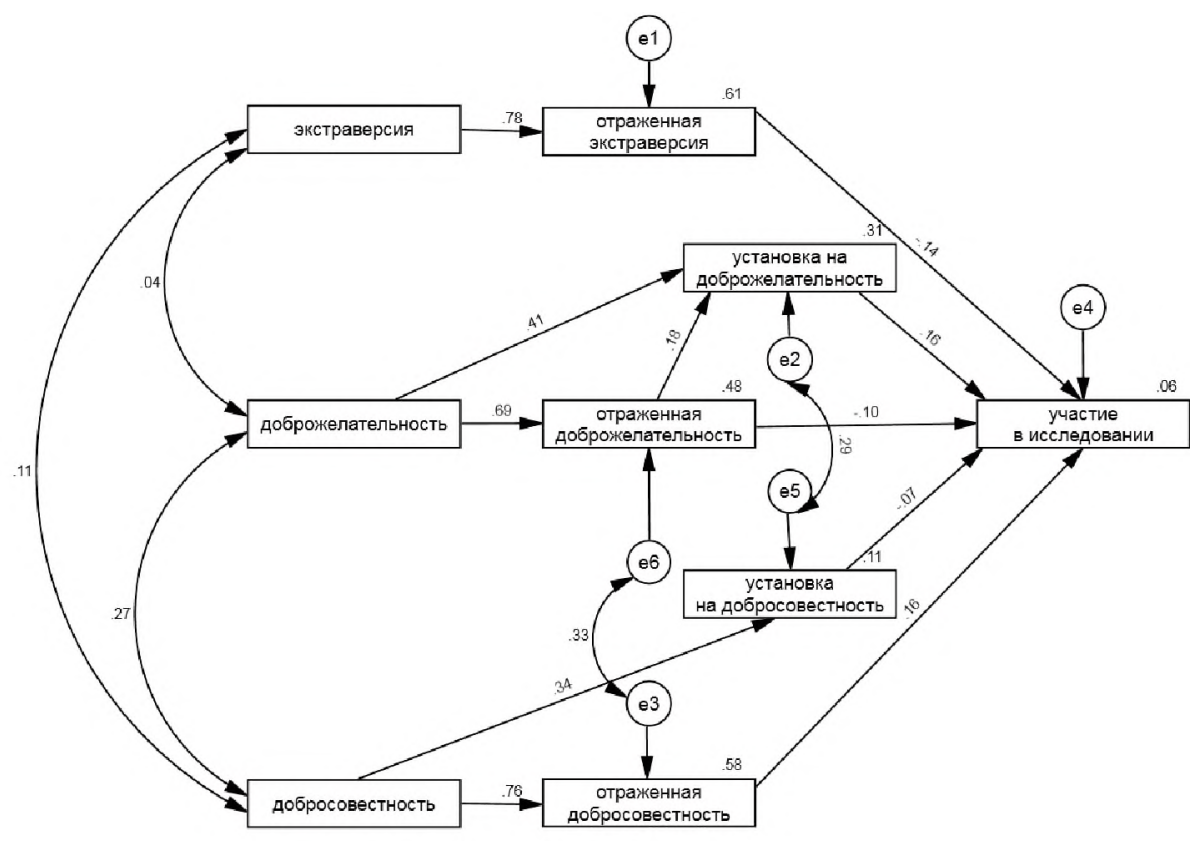

Примечание. Приведены стандартизированные регрессионные коэффициенты. Цифры над прямоугольниками - коэффициент детерминации $R^{2}$.

${ }^{7}$ Анонимный рецензент приводит свидетельства тому, что WLS надежно работает лишь на очень больших выборках (несколько тысяч наблюдений). В этой связи я, по его рекомендации, дополнительно привожу коэффициенты соответствия, полученные методом ML: $\chi^{2}(20)=59.54$, $p<0.001, \mathrm{RMR}=0.011, \mathrm{GFI}=0.988, \mathrm{CFI}=0.988, \operatorname{RMSEA}[90 \% \mathrm{CI}]=0.044[0.031 ; 0.057]$, $p($ RMSEA $<0.05)=0.769$. Таким образом, эти две оценки показали согласованные результаты. 


\section{Обсуждение}

Наши гипотезы о взаимосвязи черт личности с истощением выборки в исследовании с двумя волнами сбора данных получили частичное подтверждение. Как и предполагалось, интроверсия, доброжелательность и добросовестность предсказывали участие во втором этапе исследования. С другой стороны, открытость опыту и нейротизм этого не предсказывали. Хотя ранее полученные данные по экстраверсии противоречивы (Dollinger, Leong, 1993; Satherley et al., 2015), мы предполагали отрицательную корреляцию, поскольку шаг 2 исследования носил дистанционный характер, подразумевая работу вне класса/лаборатории и контакт с исследователем исключительно по электронной почте. Полученные данные свидетельствуют о том, что отрицательный эффект экстраверсии ожидаем, но при определенной организации исследования. Напротив, в случае очных форм организации исследования можно ожидать и положительного эффекта экстраверсии на дальнейшее участие, что было продемонстрировано ранее в контексте волонтерской деятельности (например: Omoto et al., 2010).

Вопреки предположениям открытость опыту не предсказывала участия в этапе 2. Это противоречит ранее опубликованным фактам (Dollinger, Leong, 1993; Satherley et al., 2015) и интуитивно принятой идее о том, что готовность участвовать в исследованиях связана с повышенным познавательным интересом. Этот факт особенно любопытен в связи с тем, что в качестве един- ственного стимула мы использовали обещание более детальной обратной связи. Следует, однако, обратить внимание на то, что метаоткрытость внесла слабый инкрементный вклад в предсказание участия в этапе 2 .

Продолжение участия предсказывалось доброжелательностью и добросовестностью. Иными словами, истощение выборки происходило среди респондентов, имевших враждебное отношение к другим людям (вероятно, в том числе - к исследователям), а также неспособных контролировать импульсивное поведение (в том числе - продолжить участие в исследовании)

Данные регрессионного анализа показали, что эффект пола оставался независимым от эффектов характеристик личности. Это согласуется, например, с предыдущими данными (Dollinger, Leong, 1993), в которых также не было обнаружено существенных взаимодействий (в терминах ANOVA) пола и согласия на дальнейшее участие в исследовании.

Вклады черт личности были элиминированы PXА - установками на черты и метачертами. В частности, вклад экстраверсии был опосредован метаэкстраверсией, а вклады доброжелательности и добросовестности установками на эти черты, а также их метачертами. Содержательно это может означать следующее. При решении продолжать участие в исследовании на индивида может влиять то, насколько он считает, что выглядит экстравертированным, доброжелательным и добросовестным в глазах значимых для него людей. Если индивид полагал, что его считают общительным и самоуверенным (метаэкстраверсия), это 
могло явиться для него фактором, останавливающим перед участием в заочном компьютерном тестировании. Аналогично, если индивид полагал, что значимые другие считают его добросовестным, это способствовало его положительному решению о дальнейшем участии.

В части доброжелательности аналогичный эффект обеспечивался положительной установкой на эту черту. Мнение индивида о том, что «быть доброжелательным это хорошо», способствовало тому, что он принимал участие в исследовании. Напротив, мнение о том, что в доброжелательности как черте нет ничего хорошего, препятствовало дальнейшему участию.

Особый интерес представляет тот факт, что метадоброжелательность и установка на добросовестность производили дополнительный и отрицательный вклад в вероятность участия в шаге 2. Например, доброжелательность амбивалентно сказывалась на истощении выборки: с одной стороны, она способствовала дальнейшему участию индивида - через формирование положительной установки к этой черте личности. Обыденная логика могла быть такой: «Хорошо быть доброжелательным, я - доброжелательный, следовательно, я продолжаю участвовать в исследовании». Однако «сухой остаток», выраженный в метадоброжелательности после контроля ее сопряженности с этой чертой и установкой на нее, препятствовал дальнейшему участию. Обыденная логика в данном случае выглядит контринтуитивной: «Родители считают меня доброжелательным, я доброжелательный, следовательно, я не буду участвовать в исследовании».
Аналогичным амбивалентным образом на истощении выборки сказывалась добросовестность: с одной стороны, она способствовала дальнейшему участию - через метадобросовестность: «родители считают меня добросовестным, я - добросовестный, следовательно, я продолжаю участвовать в исследовании». Однако «сухой остаток» - теперь уже установки на добросовестность препятствовал дальнейшему участию: «мне нравится добросовестность, я - добросовестный, и я не участвую в исследовании». Ранее аналогичные амбивалентные эффекты были получены в контексте академической успеваемости (Щебетенко, 2015а) и общей структуры РХА (Щебетенко, 2015б).

Чем их можно объяснить? Начиная, по крайней мере, с классических работ Фрейда (1990), множественность детерминации поведения индивида считается в психологии ключевым постулатом. Это породило возникновение ряда теорий двойственных процессов (dual-process theories; например: Chaiken, Trope, 1999). В целом такие теории различают два типа обработки информации индивидом (Smith, DeCoster, 2000): основанный на правилах и основанный на ассоциациях. В частности, в этом контексте Ф. Штрак и Р. Дойч (Strack, Deutsch, 2004) предложили рефлексивно-импульсивную модель (the reflective-impulsive model; RIM) социального поведения, которая, как нам представляется, может объяснить полученные результаты. Помимо прочего, эта модель утверждает, что импульсивная система детерминант социального поведения ориентирована на при- 
ближение и избегание как базовые мотивационные ориентации (тезис 8 RIM; cp., например: Gray, McNaughton, 2003). Частным случаем такого поведения может быть (не)участие во второй волне исследования. РХА представляют собой рефлексивную систему детерминант социального поведения (ср. тезис 4 RIM). Это означает, что PXА должны создавать путь от черт личности к поведению, основанный на рефлексии и мониторинге черт, связанных с ними метакогнитивных правилах и логике (тезис 7). Например, добросовестность и доброжелательность предполагают конструктивное социальное поведение, в частности, участие в ранее начатом исследовании. Однако после статистического контроля ковариаций сохраняется необъясненной «импульсивная» дисперсия РXА, противоречащая правилам и логике. Она может быть основана на ассоциациях и повторяющемся опыте индивида (тезис 4). Вопреки декларируемой положительной установке на добросовестность и вопреки метадоброжелательности индивид не участвует в ранее начатом исследовании. Однако, конечно, подобные спекуляции требуют более надежного эмпирическо- го свидетельства, в частности, в результате репликации результатов данного исследования.

Лонгитюдные и многоволновые исследования являются важным инструментом сбора данных в современной психологии. Вопрос о том, какие факторы могут являться причиной искажений в таких исследованиях, остается крайне актуальным. Судя по всему, черты личности и РХА могут предсказывать не только то, кто соглашается на участие в исследовании изначально, но и кто продолжает в нем участвовать спустя некоторое время после его начала. В то же время следует обратить внимание на достаточно небольшие значения коэффициентов детерминации в модели, тестировавшейся в данном исследовании. Таким образом, хотя представленное исследование скорее защищает идею статистически значимого вклада личностных характеристик в искажения выборки, эти эффекты следует отнести к разряду малых. Тем не менее общий вывод из данной работы заключается в том, что исследователи при использовании лонгитюдных методов должны проявлять осторожность в своих выводах касательно личностных характеристик, а также их конт-

\section{Литература}

Адмиральская, И. С. (2009). Поиск и привлечение респондентов как этап экспериментального исследования супружества. Психология. Журнал Высией иколы экономики, 6(2), 153-160.

Балабина, А. Д. (2015). Рефлексивные адаптации характера и социометрический статус. Вестиик Пермского уииверситета. Философия. Психология. Социология, 2(22), 55-64.

Власов, В. В. (2007). Систематические ошибки и вмешивающиеся факторы. Международный журнал медицинской практики, 3, 18-29.

Давыдов, А. А. (1990). Репрезентативность выборки. Социологииеские исследовамия, 1, $115-121$. Дружинин, В. Н. (2000). Экспериментальная психология. СПб.: Питер. 
Корнилов, С. А. (2011). Лонгитюдные исследования: теория и методы. Экспериментальная психология, 4(4), 101-116.

Косарев, В. В., Бабанов, С. А. (2009). Этика биомедицинских исследований: проблемы и решения. Медиинский альманах, 4, 41-45.

Тренева, М. С., Мунб́лит, Д. Б., Пампура, А. Н. (2014). Добровольное согласие родителей на участие в научном исследовании: смещение выборки относительно популяции? Российский вестник перинатологии и педиатрии, 59(1), 82-87.

Фрейд, 3. (1990). Психология бессознательного: сбортик произведений. М.: Просвещение.

Чепракова, В. А., Воронина, Л. А., Цыган, В. Н. (2011). Биоэтика. История, правовое регулирование исследований с участием человека. Вестник Российской военио-медиинской академии, $1,222-227$.

Шебетенко, С. А. (2015а). Отраженные установки на черты личности как предиктор успеваемости студентов. Психология и психотехника, 1(76), 70-82. doi:10.7256/2070-8955.2015.1.13526

Шебетенко, С. А. (2015б). Рефлексивные адаптации характера в пятифакторной теории личности. Психологический журнал, 36(6), 55-65.

Щебетенко, С. А., Тютикова, Е. А. (2015). «Картина хороша, потому что хороша открытость опыту»: Опосредующая роль установок на черты личности в индивидуальных различиях отношения к живописи. Психология. Журиал Высшей иколы экономики, 12(4), 122-141.

Ссылки на зарубежные источники см. в разделе References после англоязыиного блока.

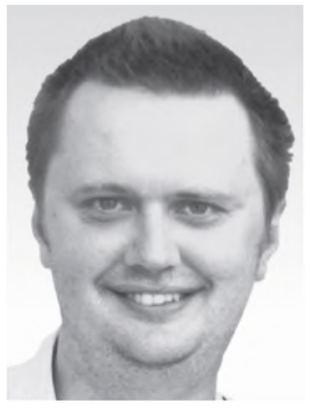

Щебетенко Сергей Александрович - профессор, кафедра психологии развития, Пермский государственный национальный исследовательский университет, кандидат психологических наук, доцент. Сфера научных интересов: психология личности и индивидуальных различий, стереотипы и предубеждения, имплицитные установки, психометрика, прикладная статистика в психологии. Контакты: shebetenko@gmail.com, shebetenko@rambler.ru

\title{
Who Continues to Participate at Stage Two of a Longitudinal Study? The Role of Personality Characteristics
}

\author{
S.A. Shchebetenko ${ }^{a}$ \\ ${ }^{a}$ Perm State University, 15 Bukireva str., Perm, 614990, Russian Federation
}

\begin{abstract}
The aim of this study was to examine whether personality traits predict sample depletion, which occurs in the studies with the two stages of data collection. Methodologically, the problem
\end{abstract}


was studied in terms of the five-factor theory of personality (McCrae, Costa, 2013). The study was conducted in two stages. At Stage 1, 1030 students participated in a psychological study in classrooms, where they fulfilled the main battery of the tests. At Stage 2 the participants completed a questionnaire off-site, and 277 participants of the main sample emailed a file with the completed test to the researcher. Agreeableness, conscientiousness, and introversion predicted that the participants will take part at Stage 2 . The logistic regression analysis estimated the contribution of the reflective characteristic adaptations - meta-traits and attitudes to traits - to these effects. Meta-traits are the individuals' judgments on how their personality traits are perceived by the significant others, in our case - by parents. Attitudes toward traits are the valent (positive/ negative) evaluations of these traits by the individuals without the direct reference to their personality. Reflective characteristic adaptations incrementally predicted to the participation at Stage 2, while the role of the traits themselves was eliminated. The depletion of the sample was predicted by various meta-traits and attitudes toward various traits. The ambivalent role of attitudes toward traits and meta-traits has been further discussed in terms of the reflectiveimpulsive model by F. Strack and R. Deutsch. A model was empirically supported, in which the personality traits (extraversion, agreeableness, conscientiousness) related with depletion of the sample indirectly, via reflective characteristic adaptations. Relatively small values of the coefficients of determination presumes that the role of personality characteristics in sample depletion is rather small, but yet substantial.

Keywords: reflexive characteristic adaptations, meta-traits, attitudes towards traits.

\section{References}

Admiral'skaya, I. S. (2009). The search and recruiting of respondents as a stage of an experimental study of marriage. Psychology. Joumal of Higher School of Economics, 6(2), 153-160. (in Russian)

American Psychological Association. (2010). Ethical principles of psychologists and code of conduct. Retrieved from http://www.apa.org/ethics/code/principles.pdf

Ashton, M. C., \& Lee, K. (2007). Empirical, theoretical, and practical advantages of the HEXACO model of personality structure. Personality and Social Psychology Review, 11, 150-166. doi:10.1177/1088868306294907

Balabina, A. D. (2015). Reflexive characteristic adaptations and sociometric status. Perm University Herald. Series "Philosophy. Psychology. Sociology", 2(22), 55-64. (in Russian)

Browne, M. W. (1984). Asymptotically distribution-free methods for the analysis of covariance structures. British Joumal of Mathematical and Statistical Psychology, 37, 62-83. doi:10.1111/j.20448317.1984.tb00789.x

Chaiken, S., \& Trope, Y. (Eds.). (1999). Dual-process theories in social psychology. New York: Guilford Press.

Cheprakova, V. A., Voronina, L. A., \& Tsygan, V. N. (2011). Bioethics. History, juridical regulation of the human-involving research. Vestnik Rossiiskoi Voenno-Meditsinskoi Akademii, 1, 222-227. (in Russian)

Church, A. H. (1993). Estimating the effect of incentives on mail survey response rates: A meta-analysis. Public Opinion Quarterly, 57, 62-79. doi:10.1086/269355

Davydov, A. A. (1990). The sample representativeness Sotsiologicheskie Issledovaniya, 1, 115-121. (in Russian) 
Dollinger, S. J., \& Leong, F. T. L. (1993). Volunteer bias and the five-factor model. The Journal of Psychology, 127, 29-36. doi:10.1080/00223980.1993.9915540

Druzhinin, V. N. (2000). Experimental psychology. Saint Petersburg: Piter. (in Russian)

Flora, D. B., \& Curran, P. J. (2004). An empirical evaluation of alternative methods of estimation for confirmatory factor analysis with ordinal data. Psychological Methods, 9, 466-491. doi:10.1037/1082-989X.9.4.466

Freud, S. (1990). The psychology of unconscious: A collection of works. Moscow: Prosveshchenie. (in Russian)

Gallego, A., \& Oberski, D. (2012). Personality and political participation: The mediation hypothesis. Political Behavior, 34, 425-451. doi:10.1007/s11109-011-9168-7

Goldberg, L. R. (1993). The structure of phenotypic personality traits. American Psychologist, 48, 26 34. doi:10.1037/0003-066X.48.1.26

Gray, J. A., \& McNaughton, N. (2003). The neuropsychology of anxiety: An enquiry into the function of the septo-hippocampal system. Oxford, UK: Oxford University Press.

Groves, R. M., Singer, E., \& Corning, A. (2000). Leverage-saliency theory of survey participation: Description and an illustration. The Public Opinion Quarterly, 64, 299-308. Retrieved from http://www.jstor.org/stable/3078721

Hilbig, B. E., Zettler, I., Moshagen, M., \& Heydasch, T. (2013). Tracing the path from personality via cooperativeness - to conservation. European Journal of Personality, 27, 319-327. doi: $10.1002 /$ per. 1856

John, O. P., Donahue, E. M., \& Kentle, R. L. (1991). The Big Five Inventory - Versions $4 a$ and 54. Berkeley, CA: University of California, Berkeley/Institute of Personality and Social Research.

John, O. P., Naumann, L. P., \& Soto, C. J. (2008). Paradigm shift to the integrative Big Five trait taxonomy: History, measurement, and conceptual issues. In O. P. John, R. W. Robins, \& L. A. Pervin (Eds.), Handbook of personality: Theory and research (pp. 114-158). New York: Guilford Press.

Kahneman, D., Krueger, A. B., Schkade, D. A., Schwarz, N., \& Stone, A. A. (2004). A survey method for characterizing daily life experience: The day reconstruction method. Science, 306(5702), $1776-$ 1780. doi:10.1126/science. 1103572

Kornilov, S. A. (2011). Longitudinal studies: theory and methods. Eksperimental'naya psihologiya [Experimental Psychology (Russia)], 4(4), 101-116. (in Russian)

Kosarev, V. V., \& Babanov, S. A. (2009). The ethics of biomedical research: Problems and solutions. Meditsinskii Almanakh, 4, 41-45. (in Russian)

Lubin, B., Levitt, E. E., \& Zuckerman, M. (1962). Some personality differences between responders and nonresponders to a survey questionnaire. Joumal of Consulting Psychology, 26, 192. doi: $10.1037 / \mathrm{h} 0048697$

Lugtig, P. (2014). Panel attrition: Separating stayers, fast attriters, gradual attriters, and lurkers. Sociological Methods and Research, 43, 699-723. doi:10.1177/0049124113520305

Malloy, T. E., Albright, L., Kenny, D. A., Agatstein, F., \& Winquist, L. (1997). Interpersonal perception and metaperception in nonoverlapping social groups. Joumal of Personality and Social Psychology, 72, 390-398. doi:10.1037/0022-3514.72.2.390

McCrae, R. R., \& Costa Jr., P. T. (2013). Introduction to the empirical and theoretical status of the five-factor model of personality traits. In T. A. Widiger \& P. T. Costa Jr. (Eds.), Personality disorders and the five-factor model of personality (3rd ed., pp. 15-27). Washington, DC: American Psychological Association.

Menard, S. (2002). Longitudinal research. Thousand Oaks, CA: Sage. 
Omoto, A. M., Snyder, M., \& Hackett, J. D. (2010). Personality and motivational antecedents of activism and civic engagement. Joumal of Personality, 78, 1703-1734. doi:10.1111/j.14676494.2010.00667.x

Ployhart, R. E., \& Vandenberg, R. J. (2010). Longitudinal research: The theory, design, and analysis of change. Joumal of Management, 36, 94-120. doi:10.1177/0149206309352110

Richter, D., Körtner, J. L., \& Saßenroth, D. (2014). Personality has minor effects on panel attrition. Joumal of Research in Personality, 53, 31-35. doi:10.1016/j.jrp.2014.08.001

Roberts, B. W., Walton, K. E., \& Viechtbauer, W. (2006). Patterns of mean-level change in personality traits across the life course: A meta-analysis of longitudinal studies. Psychological Bulletin, 132, 125. doi:10.1037/0033-2909.132.1.1

Rogelberg, S. G., Conway, J. M., Sederburg, M. E., Spitzmüller, C., Aziz, S., \& Knight, W. E. (2003). Profiling active and passive nonrespondents to an organizational survey. Joumal of Applied Psychology, 88, 1104-1114. doi:10.1037/0021-9010.88.6.1104

Rosenthal, R., \& Rosnow, R. L. (1975). The volunteer subject (Vol. 14). Oxford, UK: John Wiley \& Sons.

Saliba, A., \& Ostojic, P. (2014). Personality and participation: Who volunteers to participate in studies. Psychology, 5, 230-243. doi:10.4236/psych.2014.53034

Salthouse, T. A. (2014). Selectivity of attrition in longitudinal studies of cognitive functioning. The Joumals of Gerontology Series B: Psychological Sciences and Social Sciences, 69, 567-574. doi:10.1093/geronb/gbt046

Saßenroth, D. (2013). The impact of personality on participation decisions in surveys: A contribution to the discussion on unit nonresponse. Berlin: Springer.

Satherley, N., Milojev, P., Greaves, L. M., Huang, Y., Osborne, D., Bulbulia, J., \& Sibley, C. G. (2015). Demographic and psychological predictors of panel attrition: Evidence from the New Zealand Attitudes and Values Study. PLOS ONE, 10, e0121950. doi:10.1371/journal.pone.0121950

Schräpler, J.-P., Schupp, J., \& Wagner, G. G. (2010). Individual and neighborhood determinants of survey nonresponse: An analysis based on a new subsample of the German Socio-Economic Panel (SOEP), microgeographic characteristics and survey-based interviever characteristics (SSRN Scholarly Paper No. ID 1588730). Rochester, NY: Social Science Research Network. Retrieved from http://papers.ssrn.com/abstract $=1588730$

Shchebetenko, S. (2014). "The best man in the world": Attitudes toward personality traits. Psychology. Journal of the Higher School of Economics, 11(3), 129-148.

Shchebetenko, S. (2016). Reflexive characteristic adaptations within the five-factor theory: Between basic tendencies and external outcomes. Personality and Individual Differences, 101, 35-41. doi:10.1016/j.paid.2016.05.055

Shchebetenko, S. A. (2015a). Reflected attitudes to personality features as a predictor of students' academic success. Psychology and Psychotechnics, 1(76), 70-82. doi:10.7256/2070-8955.2015.1.13526 (in Russian)

Shchebetenko, S. A. (2015b). Reflexive characteristic adaptations within the five-factor theory of personality framework. Psikhologicheskii Zhumal, 36(6), 55-65. (in Russian)

Shchebetenko, S., \& Tutikova, E. (2015). "The picture is good because openness to experience is good": The mediating role of attitudes toward personality traits in individual differences in painting preferences. Psychology. Journal of Higher School of Economics, 12(4), 122-141. (in Russian)

Singer, E., \& Bossarte, R. M. (2006). Incentives for survey participation: When are they "coercive"? American Journal of Preventive Medicine, 31, 411-418. doi:10.1016/j.amepre.2006.07.013 
Smith, E. R., \& DeCoster, J. (2000). Dual-process models in social and cognitive psychology: Conceptual integration and links to underlying memory systems. Personality and Social Psychology Review, 4, 108-131. doi:10.1207/S15327957PSPR0402_01

Strack, F., \& Deutsch, R. (2004). Reflective and impulsive determinants of social behavior. Personality and Social Psychology Review, 8, 220-247. doi:10.1207/s15327957pspr0803_1

Treneva, M. S., Munblit, D. B., \& Pampura, A. N. (2014). Parents' voluntary consent to participate in research: Biased sampling in relation to the population? Rossiyskii Vestnik Perinatologii i Pediatrii [Russian Bulletin of Perinatology and Pediatrics], 59(1), 82-87. (in Russian)

Vlasov, V. V. (2007). Systematic errors and interfering factors. Mezhdunarodnyi Zhumal Meditsinskoi Praktiki, 3, 18-29. (in Russian)

Sergei A. Shchebetenko - professor, Department of Developmental Psychology, Perm State University, Ph.D.

Research area: personality, social cognition, research methodology.

E-mail: shebetenko@gmail.com, shebetenko@rambler.ru 